
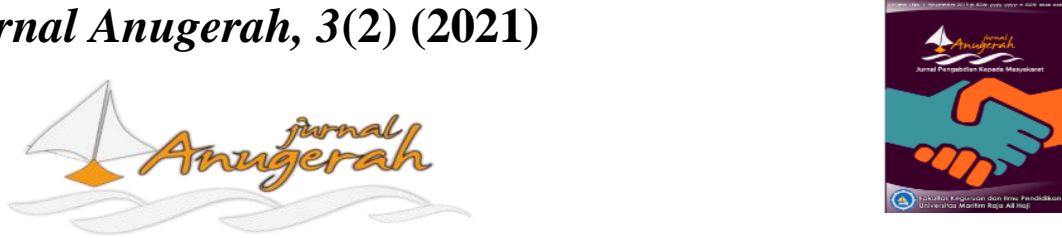

e-ISSN 2715-8179

https://ojs.umrah.ac.id/index.php/anugerah

\title{
Sosialisasi Soal-Soal Asesmen Kompetensi Minimum dengan Menggunakan Aplikasi Quizizz untuk Siswa Paket C Di PKBM Harapan Bangsa
}

\author{
Tety Kurmalasari \\ Universitas Maritim Raja Ali Haji, Tanjungpinang, Kepulauan Riau, 29111, Indonesia \\ *e-mail korespondensi: teti@umrah.ac.id
}

Pengiriman: 11 Oktober 2021; Diterima: 21 Oktober 2021; Publikasi: 30 November 2021

DOI: https://doi.org/10.31629/anugerah.v3i2.3813

\begin{abstract}
Abstrak
Kegiatan pengabdian ini bertujuan adalah untuk memberikan pemahaman tentang bentuk-bentuk soal-soal AKM dengan menggunakan media quizizz kepada peserta didik atau warga belajar kelas XII paket C pada PKBM Harapan Bangsa untuk memudahkan dalam menyelesaikan ujian Pendidikan kesetaraan yang berbasis online. Metode yang digunakan dalam sosialisasi ini dengan tiga tahap yaitu pertama, pengenalan tentang Asesmen Kompetensi Minimum (AKM) dan bentuk-bentuk soal AKM, tahap kedua latihan pengenalan soal AKM dengan menggunakan Aplikasi quizizz, peserta atau warga belajar memperaktikkan setiap langkah-langkah dan menyelesaikan soal-soal AKM didalam aplikasi quizizz tersebut. Tahap selanjutnya, pembahasan materi soal AKM pada mata pelajaran sejarah. Hasil dari pengabdian ini, warga belajar tampak menguasai empat kompetensi AKM yaitu intervensi khusus, dasar, cakap dan mahir sehingga hal ini terlihat dari hasil ujian simulasi tersebut 75\% memenuhi standar KKM. Serta dapat disimpulkan peserta didik atau warga belajar telah menguasai soal-soal literasi pada uji coba Asesmen Kompetensi Minimum (AKM) Pendidikan kesetaraan Paket C kelas XII.
\end{abstract}

Kata kunci: pembelajaran, quizizz, warga belajar, pendidikan kesetaraan

\begin{abstract}
This service activity aims to provide an understanding of the forms of AKM questions using the quizizz media to students or learning residents of class XII package C at PKBM Harapan Bangsa to make it easier to complete the online-based equality education exam. The method used in this socialization is in three stages, namely first, introduction to Minimum Competency Assessment (AKM) and forms of AKM questions, the second stage of introduction to AKM questions using the quizizz application, participants or residents learn to practice each step and solve questions. -AKM questions in the quizizz application. The next stage, the discussion of the material about AKM in history subjects. The results of this service, learning residents seem to master the four AKM competencies, namely special, basic, skilled and advanced interventions so that it can be seen from the simulation exam results that $75 \%$ meet the KKM standard. And it can be concluded that students or learning residents have mastered literacy questions in the Minimum Competency Assessment (AKM) Equivalence Educational Package C class XII trial.
\end{abstract}

Keywords: learning, quizizz, citizens of learning, equality education. 


\section{Pendahuluan}

Pada era globalisasi dan kemajuan teknologi terutama media elektronik telah membawa dampak pada proses pembelajaran dalam bidang pendidikan. Pembelajaran merupakan proses belajar mengajar yang dilakukan oleh guru dan siswa dalam keadaan tertentu untuk mencapai tujuan yang telah ditetapkan (Kosasih, 2013). Seiring dengan perkembangan zaman dan perubahan kurikulum 2013 terdapat penguatan Pendidikan karakter, kemampuan literasi dan numerasi, kompetensi pembelajaran abad 21 setara SMA / Paket C. Asesmen Kompetensi Minimum merupakan penilaian kompetensi mendasar yang dapat mengembangkan kapasitas diri dan berpartisipatif positif. Strategi pembelajaran pada warga belajar dalam menghadapi Asesmen Kompetensi Minimun (AKM) karena AKM menjadi tolak ukur evaluasi yang lebih komprehensif untuk mengukur kemampuan minimal siswa, (Nadiem, 2020). AKM terdiri dari tes kemampuan yaitu: a) Literasi merupakan kemampuan untuk memahami, menggunakan, mengevaluasi, merefleksikan berbagai jenis teks tertulis untuk mengembangkan kapasitas individu. b) Numerasi adalah kemampuan berpikir menggunakan konsep prosedur, fakta, dan alat matematika untuk menyelesaikan masalah sehari-hari pada berbagai jenis konteks yang relevan. Sehingga, perlu dilakukan evaluasi sejauh mana kemamampuan warga belajar agar mencapai hasil yang maksimum. Menurut Ady (2020) terdapat beberapa bentuk soal AKM, antara lain:

1. Pilihan ganda kompleks: adalah pertanyaan di mana beberapa jawaban dipilih dalam satu pertanyaan.

2. Mencocokkan pertanyaan: Sebuah pertanyaan yang biasanya dijawab dengan menarik garis dari satu titik ke titik lain untuk mencocokkan pertanyaan dengan jawaban yang benar.

3. Uraian singkat: pertanyaan dengan jawaban singkat, seperti angka atau kata pendek yang menyebutkan tempat, nama benda, atau jawaban lainnya.

4. Uraian: Ini adalah pertanyaan yang jawabannya lebih panjang dari kata pendek, dan kalimat jawabannya harus jelas

5. Pilihan ganda kompleks: Ini adalah pertanyaan dengan pilihan beberapa opsi, tidak homogen, dan dapat memiliki satu atau lebih jawaban.

Soal AKM sangat berbeda dengan bentuk soal Ujian Nasional sebelumnya. Soal AKM terdiri atas teks informasi dan teks fiksi, disajikan lebih utuh dengan gambar dan ilustrasi yang kuat sehingga pesan yang disampaikan lebih komprehensif, serta stimulus teks AKM bertujuan sebagai sarana menilai kompetensi dan menginspirasi, Sehingga warga belajar dan tutor perlu menyiapkn diri dalam menghadapi evaluasi yang sebentar lagi. Evaluasi adalah proses pengukuran pencapaian tujuan yang direncanakan dengan mengumpulkan dan menganalisis data atau informasi yang berguna untuk menentukan efektivitas pencapaian tujuan. Media pembelajaran merupakan hal yang sangat penting dalam proses pengajaran yang dapat menentukan keberhasilan kegiatan pembelajaran Luring Maupun Daring. Media Online merupakan media komunikasi yang pemanfaatan nya menggunakan perangkat internet (Suryawati, 2011). Sementara, Media pembelajaran daring (Online) merupakan Interaksi pembelajaran melalui internet sebagai perantara untuk mentransfer pengetahuan guru dan siswa (Kuntarto, 2017). Sehingga tes berbasis daring (online) dengan menggunakan aplikasi quizizz ini dilakukan sebagai uji coba dalam mengahadapi ujian akhir sekolah. Quizizz merupakan aplikasi game edukasi dengan narasi yang fleksibel untuk penyampaian materi dan dapat dijadikan media evaluasi pembelajaran yang menyenangkan dan menarik. Perbandingan dengan media lainnya aplikasi quizizz sangat lebih cepat terpantau langsung oleh tutor dan warga belajar yang melakukan ujian. Kuis ini berasal dari kreativitas pendidik atau tutor yang bekerja keras mereview pelajaran untuk menilai pemahaman dan daya serap siswa terhadap mata pelajaran sejarah yang di sajikan dalam bentuk latihan atau penilaian yang menarik dan dapat dilakukan menggunakan gadget pribadi di dalam maupun di luar kelas dengan media (online) menggunakan aplikasi quizizz. 
Program Pendidikan sederajat juga telah menerapkan model pembelajaran yang lebih participatif agar warga belajar dapat terlibat dalam proses pembelajaran secara lebih aktif. Sistem Satuan Kredit Kompetensi (SKK) ini juga telah diterapkan oleh Program packet C. SKK memungkinkan peserta didik dapat menentukan pembelajarannya sesuai dengan kemampuan dan minatnya, sehingga diharapkan warga belajar dapat menyelesaikan pembelajaran dalam waktu yang relatif singkat dan memberikan kemungkinan untuk mentransfer kemampuannya ke dalam Pendidikan formal. Pada pembelajaran sistem SKK warga belajar diharapkan: a). Mandiri, Belajar menggunakan modul dan b). Tutorial, yaitu belajar Luring maupun Daring. Pada Tahun 2007, Permendiknas No.14 tentang Pemerataan Standar Pendidikan yaitu kelompok mata pelajaran iptek dalam Paket C setara SMA /MA bertujuan untuk memperoleh kemampuan dasar iptek dan mengolah iptek secara kritis, kreatif dan mandiri.

Demi menghadapi ujian sekolah Tutor harus lebih berinovatif dan kreatif membuat metode tes berbasis online yang dapat menyiapkan lulusan warga belajar lebih kreatif, inovatif, produktif dan berdaya saing. Berdasarkan hasil pantauan situasi, para tutor di PKBM Harapan Bangsa belum melakukan uji coba tes soal-soal literasi AKM berbasis online dengan menggunakan aplikasi berbasis online. Sehingga tujuan dari pengabdian ini untuk memberikan pemahaman soal-soal AKM berbentuk literasi kepada warga belajar PKBM Harapan Bangsa dengan menggunakan media quizizz agar warga belajar lebih terlatih dan lebih mudah menghadapi ujian kesetaraan. Berdasarkan hasil analisis ini, maka pelaksanaan tes berbasis online ini bertema "Sosialisasi Soal-Soal Asesmen Kompetensi Minimum dengan Menggunakan Aplikasi Quizizz Untuk Siswa Paket C di PKBM Harapan Bangsa".

\section{Metode}

Metode yang dilakukan dalam pengabdian ini yaitu sosialisasi dan pelatihan pengenalan soal-soal Asesmen Kompetensi Minimum dengan Aplikasi Quizizz kepada warga belajar PKBM Harapan Bangsa. Berikut ini diuraikan tahapan kegiatan pelaksanaan antara lain:

a. Persiapan

Pada tahap persiapan dilakukan penentuan dan survei lokasi target serta pembuatan dan penyusunan soal literasi dari beberapa referensi sesuai dengan instrumen AKM dilanjutkan dengan tahap validasi oleh waka dan pimpinan PKBM Harapan Bangsa.

b. Pelaksanaan Pengabdian

Selanjutnya, dilakukan sosialisasi dan uji coba tentang soal literasi dengan penggunaan media berbasis online. Pada tahap pelaksanaan pengabdian ini terdapat tiga tahapan, yaitu 1). Pengenalan soal-soal literasi dengan media quizizz. 2). Menyelesaikan soal-soal literasi dengan menggunakan aplikasi quizizz.

c. Pembahasan dan diskusi tentang soal-soal AKM.

\section{Hasil dan Pembahasan}

Kegiatan pengabdian dilaksanakan selama 4 hari pertemuan. Kegiatan tersebut dilaksanakan pada tanggal 09, 10, 11 dan 12 Oktober 2021. Peserta kegiatan berjumlah 20 orang warga belajar Paket C PKBM Harapan Bangsa Tanjungpinang. Kegiatan sosialisasi pertama dan kedua dilaksanakan pada hari Sabtu dan Minggu 09 dan 10 Oktober 2021. Dimana kegiatan ini dilakukan didalam ruangan kelas. Ujian tes quizizz ini dilaksanakan pada pukul 09.00 WIB yang diawali dengan pembukaan oleh ketua PKBM Harapan Bangsa sebagaimana terlihat pada Tabel 1.

Tabel 1

Jadwal Pelaksanaan Kegiatan Pengabdian 
JURNAL ANUGERAH, November 2021; 3(2): 111-117

e-ISSN 2715-8179

$\begin{array}{lll}\text { Pertemuan } & \text { Hari, Tanggal Materi }\end{array}$

I $\quad$ Sabtu, 09 Oktober 2021

Sosialisasi tentang pengenalan soal-soal Asesmen Kompetensi Minimum

dengan aplikasi quizizz

II-III Minggu-Senin,

10-11 Oktober 2021

IV Selasa, 12 Oktober 2021
Mempraktikkan soal-soal AKM dengan aplikasi quizizz.

Pemaparan hasil tes dan diskusi soal-soal mata pelajaran sejarah

Adapun dalam kata sambutan yang disampaikan ucapan terima kasih kepada dosen UMRAH kemudian berharap bahwa kegiatan ini bisan berjalan lancar. Warga belajar dapat melaksanakan ujian tes quizizz dengan antusias dan semangat. Tes berbasis online ini diharapkan dapat bermanfaat bagi warga belajar. Berikut langkah-langkah memasuki aplikasi quizizz dan bentuk soal AKM, yaitu:

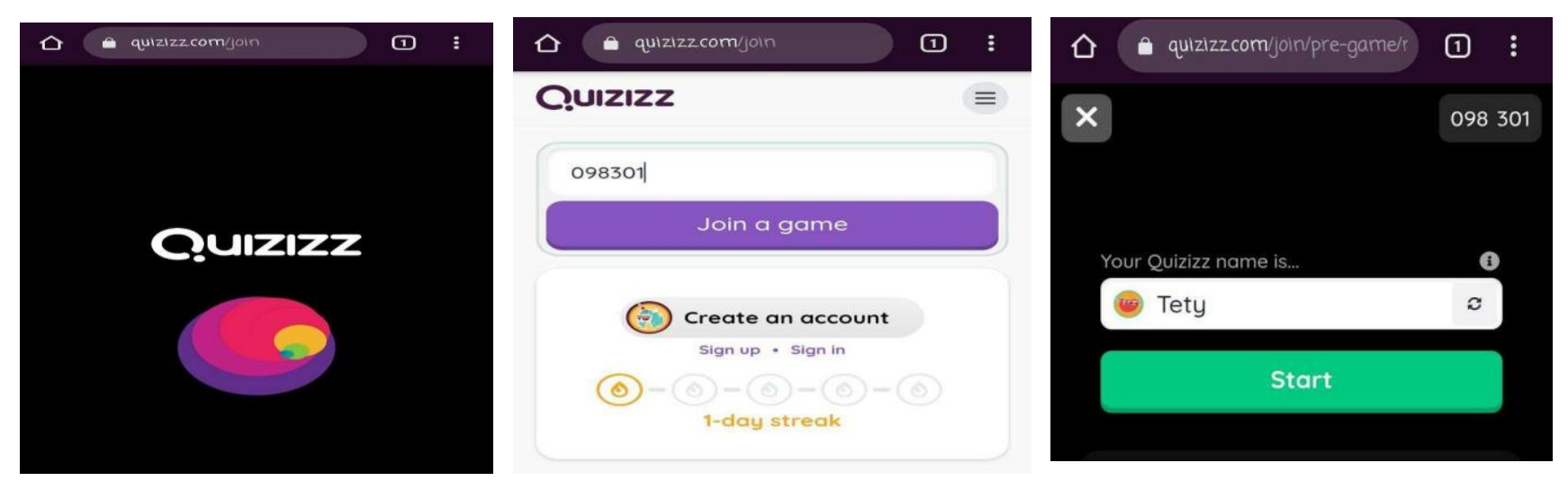

Gambar 1. Langkah-langkah masuk aplikasi quizizz

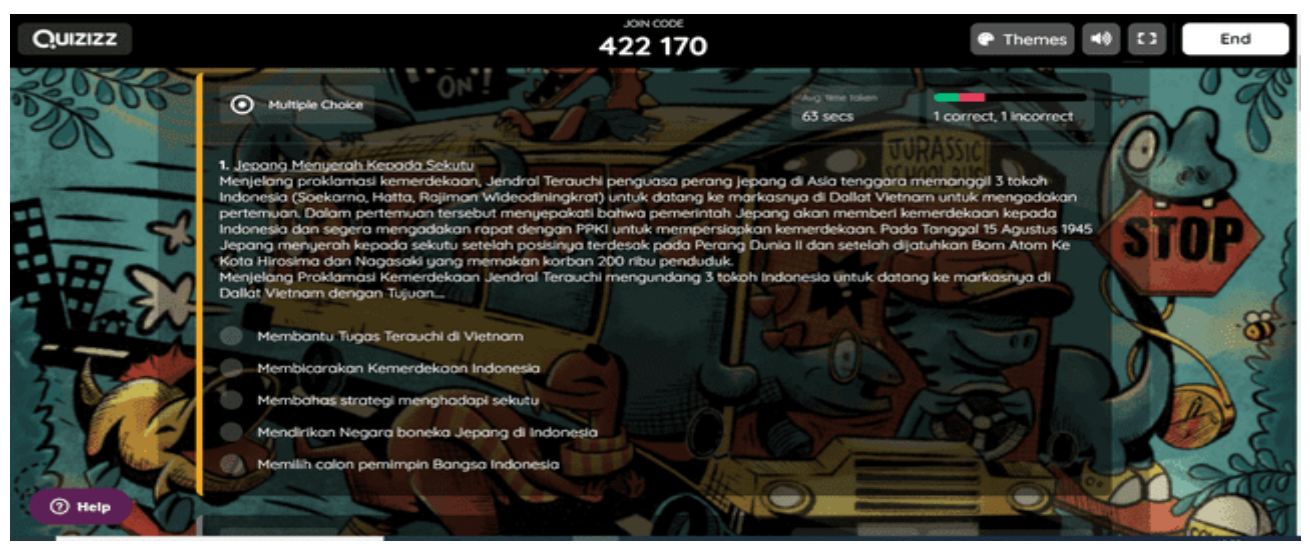

Gambar 2. Bentuk-bentuk soal AKM dalam bentuk literasi

Setelah selesai pembukaan dilaksanakan, dilanjutkan dengan sosialisasi pengenalan soal-soal Asesmen Kompetensi (AKM) disampaikan oleh Tety Kurmalasari. Selanjutnya, penjelasan langkah-langkah 
menggunakan akun quizizz diantaranya peserta harus memiliki akun google, memasukkan kode join, menginput nama lengkap dan menyelesaikan soal sebagaimana terlihat pada gambar di bawah ini:

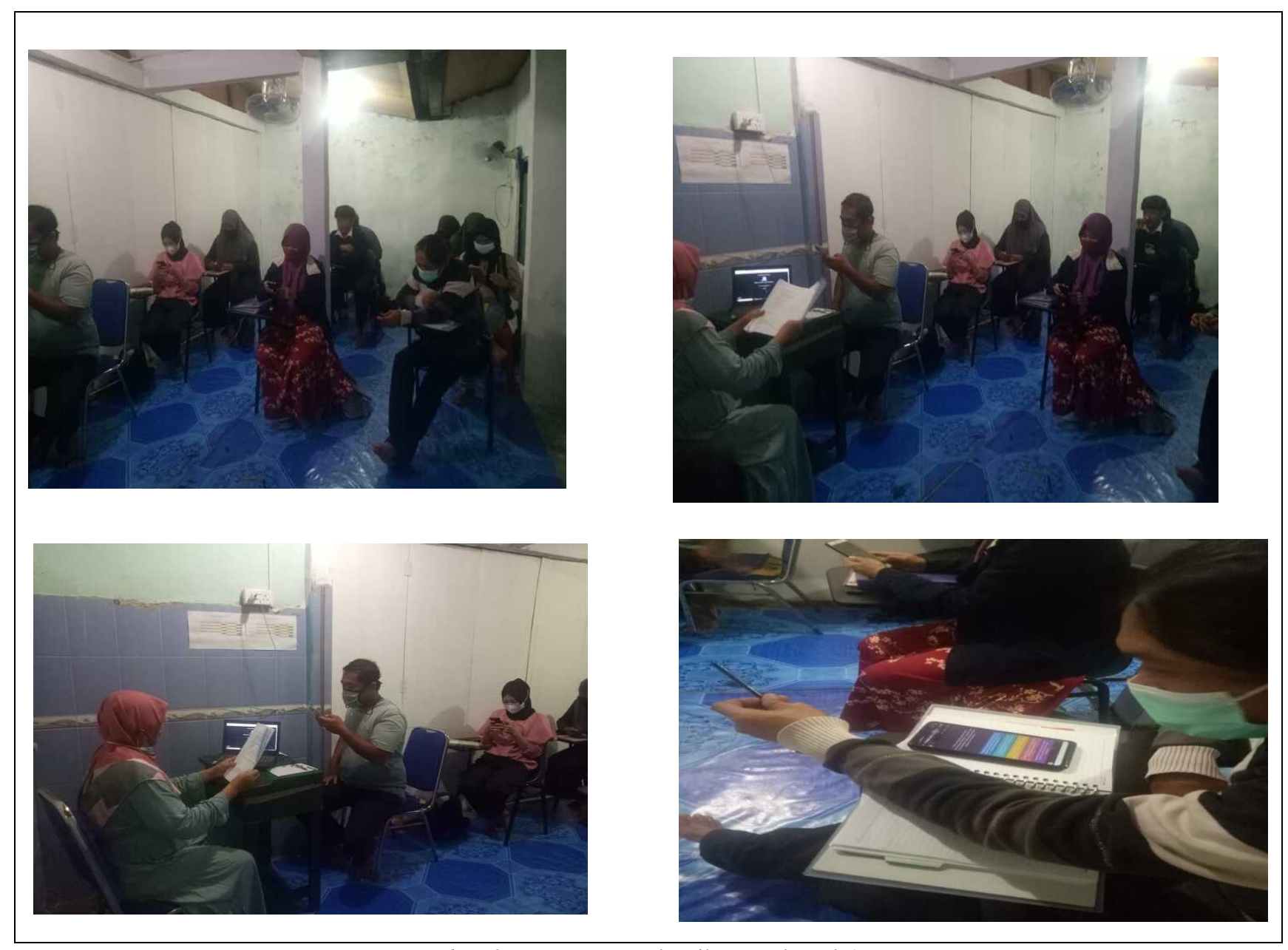

Gambar 3. Proses menyelesaikan soal-soal AKM

Pada pertemuan keempat dilaksanakan pada hari Selasa 12 Oktober 2021 yaitu dengan melanjutkan pemaparan hasil dari ujian dan tanya jawab/diskusi serta pembahasan soal-soal AKM yang disampaikan oleh Tety Kurmalasari. Berdasarkan contoh hasil penelitian Astriyani (2021) dengan menerapkan aplikasi Thatquiz pada mata pelajaran matematika, guru sudah dapat menguasai langkah dan proses membuat soal sebagai pembelajaran online berbasis teknologi internet dan Asikin (2019), hasil dari kegiatan mendapat respons positif dari guru-guru serta sikap positif untuk mengaplikasikan pembelajaran berbasis Virtual Reality. Menurut Asrijanty (2020), dari hasil AKM terdapat empat tingkat kompetensi yaitu : 1) Tingkat Intervensi Khusus, warga belajar akan terlatih kemampuan literasi membaca. 2) Dasar, warga belajar mampu mengambil informasi eksplisit yang ada dalam teks dan dapat menarik kesimpulan. 3) Cakap, Warga belajar mampu memahami konsep dan manarik kesimpulan yang relevan. 4) Mahir, warga belajar mampu memahami isi bacaan dan merefleksikan isi teks. Sehingga, berdasarkan hasil simulasi soal-soal AKM berbasis online secara umum warga belajar telah memahami soal-soal literasi dan mencapai $75 \%$ nilai KKM. Sebagaimana terlihat pada grafik di bawah ini: 


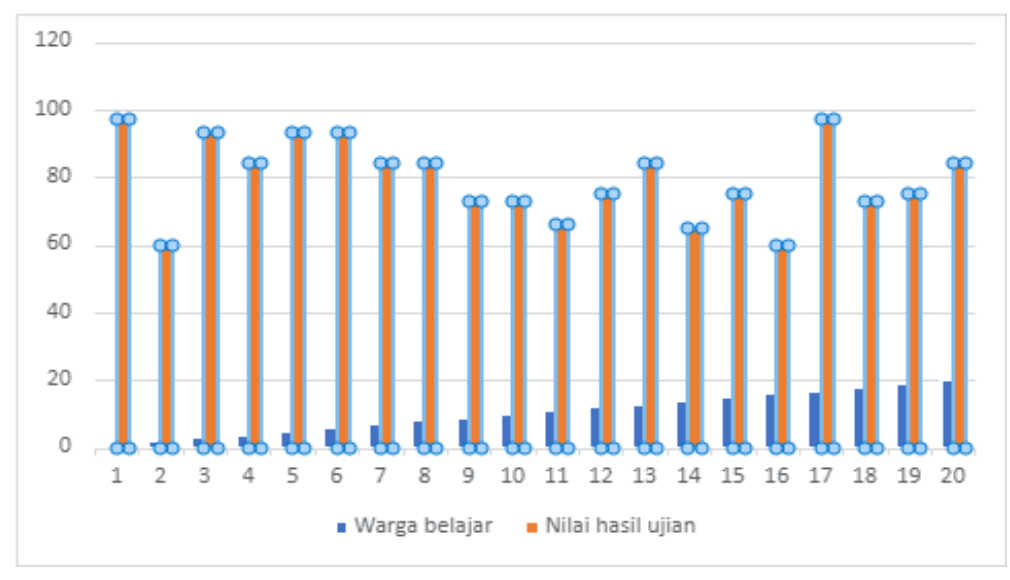

Grafik 1. Pemaparan Hasil Ujian dengan menggunakan Media Quizizz.

\section{Kesimpulan}

Kegiatan ini telah dilaksanakan di PKBM Harapan Bangsa Tanjungpinang berjalan kondusif dan warga belajar sangat antusias dalam mengikuti sosialisasi pengabdian ini. Sehingga hasil dari pengabdian ini sangat berdampak positif dan bermanfaat terhadap warga belajar dalam menyelesaikan soal-soal AKM dalam bentuk literasi, dimana yang selama ini peserta didik atau warga belajar belum memahami dan soal AKM bentuk lieterasi serta belum pernah menggunakan Aplikasi berbasis online.

\section{Saran}

Setelah kegiatan sosialisasi berakhir, ada beberapa masukan dari PKBM Harapan Bangsa Tanjungpinang yaitu membuat kegiatan pemanfaatan soal-soal AKM. Hal ini mengingat pentingnya memahami pembuatan soal AKM dalam bentuk literasi dan numerasi untuk pelaksanaan ujian semester ganjil maupun semester genap.

\section{Ucapan Terima Kasih}

1. Terima kasih kepada Dekan Fakultas Bahasa dan Sastra Indonesia yang telah memberikan kesempatan dalam melaksanakan kegiatan pengabdian.

2. Terima kasih kepada Ketua PKBM Harapan Bangsa yang telah memberikan kesempatan, tempat dan waktu dalam melaksanakan kegiatan pengabdian.

\section{Referensi}

A. (2021). Pengertian tujuan dan contoh AKM. Retrieved from https://www.searchpengertian.com /2020/12/soal-akm-pengertian-tujuan-dan-contoh.html.

Ady, Saputra. (2020). Telaah bentuk soal akm. Seminar Nasional DPP. Yogyakarta: DPD FTPKN.

Alfari, Shabrina. (2020). Contoh soal AKM Numerasi dan Literasi di Asesmen Nasional 2021 Retrieved from https://www.ruangguru.com/blog/contoh-soal-akm-numerasi-dan-literasi

Asikin, dkk, (2019). Pelatihan pemanfaatan media pembelajaran berbasis virtual reality untuk guru-guru IPA Kota Tanjungpinang. Jurnal Anugerah, 1(2): 71-76. 
Asrijanty. (2020). AKM dan implikasinya pada pembelajaran. Jakarta: Pusat Asesmen dan Pembelajaran, Kemendikbud.

Astriyani, Dkk. (2021). Pemanfaatan aplikasi daring thatquiz.org untuk mengembangkan tes berbasis online pada pembelajaran matematika. Abdimas Pedagogi, 4(1).

Gunawan, dkk. (2017). Sejarah Indonesia. Jakarta: Pusat Kurikulum dan Perbukuan, Balitbang, Kemendikbud.

Kosasih, Nandang. (2013). Pembelajaran quantum dan optimalisasi kecerdasan. Bandung: Alfabeta.

Kuntarto, E. (2017). Keefektifan model pembelajaran daring dalam perkuliahan bahasa indonesia diperguruan tinggi. Indonesia Languege Education and Literature, 3, 102.

Ramli Muhammad. (2012). Media teknologi pembelajaran. Banjarmasin: IAIN Antasari Press.

Sadirman, Lestariningsih. (2017). Sejarah Indonesia kelas 11. Jakarta. Pusat Kurikulum dan Perbukuan, Balitbang, Kemendikbud.

Suryawati, Indah. (2011). Jurnalistik suatu pengantar: teori \& praktik. Bogor: Ghalia Indonesia.

Syafnidawaty. (2020). Apa itu evaluasi. Retrieved from https://raharja.ac.id/2020/11/13/apa-itu-evaluasi. 